\title{
A comparative evaluation of neoadjuvant chemotherapy followed by concomitant chemoradiation versus accelerated radiation therapy versus conventional radiation therapy in a locally advanced head and neck carcinoma
}

\begin{abstract}
Context: Head and neck cancers (HNCs) include malignancies of oral cavity, nasopharynx, oropharynx, hypopharynx, larynx, paranasal sinuses, and major and minor salivary glands. Worldwide incidence of HNC cases is $4.8 \%$, whereas in India, it is $14.3 \%$.

Aims: Evaluation and comparison of the efficacy, tolerability, and toxicity of neoadjuvant chemotherapy (NACT) with docetaxel, carboplatin, and 5 -fluorouracil (TPF) followed by concomitant chemoradiation in one group, accelerated radiation therapy (RT) in second group, and conventional RT in third group.

Subjects and Methods: The present randomized prospective study was conducted on locally advanced head and neck carcinoma patients who were randomly divided into three groups. All patients received NACT with 3-weekly TPF, for 3-courses. Group I-patients received concomitant conventional RT, 64 Gy/32 fractions/6.2-week along with three weekly carboplatin $300 \mathrm{mg} / \mathrm{m}^{2}$ 3-cycles. Group II-patients received accelerated RT given six fractions per week, total dose 64 Gy/32 fractions/5.2-week. Group III-patients received conventional RT, 64 Gy/32 fractions/6.2-week.

Results: The overall response rate to NACT was $100 \%$ in all groups. At last follow-up, in Group I - 52\% remained alive with no evidence of disease (NED), 39\% remained alive with residual disease, and 9\% had locoregional recurrence. In Group II - 46\% remained alive with NED, $46 \%$ remained alive with disease, $8 \%$ had locoregional recurrence, whereas in Group III - 40\% remained alive with NED, 44\% remained alive with disease, and $16 \%$ had locoregional recurrence.

Conclusions: NACT followed by concomitant chemoradiation is a better treatment protocol as compared to accelerated RT or conventional radiotherapy, in terms of better complete response rates with acceptable toxicity profile.
\end{abstract}

Keywords: Accelerated radiation, concomitant chemoradiation, conventional radiation, head and neck cancer, locally advanced head and neck carcinoma

\section{INTRODUCTION}

Globally, newly diagnosed head and neck cancer (HNC) cases are 686,328 annually which is $4.8 \%$ of all cancers and deaths due to HNC are 375,665 which is $4.6 \%$ of all cancers. Newly diagnosed HNC cases in India are 145,087 annually, which are $14.3 \%$ of all cancers and deaths are 105,247 , which are $15.4 \%$ of all cancer deaths. ${ }^{[1]}$ Malignancies of oral cavity, nasopharynx, oropharynx, hypopharynx, larynx, paranasal sinuses, and major and minor salivary glands constitute

\begin{tabular}{|l|c|}
\hline \multicolumn{2}{|c|}{ Access this article online } \\
\hline \multirow{2}{*}{$\begin{array}{l}\text { Website: } \\
\text { www.asjo.in }\end{array}$} & Quick Response Code \\
\hline \multirow{2}{*}{$\begin{array}{l}\text { DOI: } \\
\text { 10.4103/2454-6798.209331 }\end{array}$} & D \\
& \\
\hline
\end{tabular}

Garima Malik, Anil Kumar Dhull, Rajeev Atri, Vivek Kaushal

Department of Radiation Oncology, Regional Cancer Centre, Pt. B. D. Sharma Post Graduate Institute of Medical Sciences, Rohtak, Haryana, India

Address for correspondence: Dr. Anil Kumar Dhull, Department of Radiation Oncology, Regional Cancer Centre, Pt. B. D. Sharma Post Graduate Institute of Medical Sciences, P. O. Box: 100, GPO, Rohtak - 124 001, Haryana, India. E-mail: anilkdhull@gmail.com

This is an open access article distributed under the terms of the Creative Commons Attribution-NonCommercial-ShareAlike 3.0 License, which allows others to remix, tweak, and build upon the work non-commercially, as long as the author is credited and the new creations are licensed under the identical terms.

For reprints contact: reprints@medknow.com

How to cite this article: Malik G, Dhull AK, Atri R, Kaushal V. A comparative evaluation of neoadjuvant chemotherapy followed by concomitant chemoradiation versus accelerated radiation therapy versus conventional radiation therapy in a locally advanced head and neck carcinoma. Asian J Oncol 2017;3:59-65. 
HNCs, and majority of them arise from the surface epithelium and are squamous cell carcinoma (SCC). ${ }^{[2]}$ The dominant risk factors for the development of HNCs are tobacco and alcohol use. $^{[3,4]}$ The most important determinant of prognosis is stage at diagnosis. The 5-year survival for Stage I patients exceeds $80 \%$ but is $<40 \%$ in locally advanced head and neck carcinoma (LAHNC). ${ }^{[5]}$

In general, either surgery or radiation is effective as single-modality therapy for patients with early-stage disease (Stage I or II) for most sites. ${ }^{[5]}$ LAHNC are usually treated with combination therapy including surgery, radiation, and chemotherapy $(\mathrm{CT}) \cdot^{[5,6]}$

Neoadjuvant CT (NACT) is aimed at both the disseminated disease and the primary tumor. It may reduce the number of clonogenic cells and cause the reoxygenation of the surviving hypoxic cells, both of which render tumors more controllable by radiation. NACT followed by definitive radiation therapy (RT) has been studied for organ preservation in patients with locally advanced cancers of the larynx and of the hypopharynx. NACT may also be used as a method to predict tumor response to chemoradiation. ${ }^{[7]}$

Radiation may be more effective for controlling the localized primary tumor, because it can be aimed and large doses given, but it is ineffective against disseminated disease. CT, on the other hand, may be able to cope with micro-metastases, whereas it could not control the larger primary tumor. ${ }^{[8]}$ In LAHNC, carboplatin and cisplatin both have been found to produce a survival benefit when added to RT. Although it appears that cisplatin may be more active, carboplatin is better tolerated. ${ }^{[9]}$

The rationale for accelerating radiation schedules is predicated on tumor cells undergoing accelerated repopulation during the treatment course after a lag time. Shortening of overall treatment time, lessen the total dose of radiation wasted in compensating for accelerated tumor cell repopulation during treatment. ${ }^{[10]}$

NACT with docetaxel, carboplatin, and 5-fluorouracil (TPF) regimen is known to decrease tumor size and improve survival in LAHNC. Following NACT, patients are usually treated by concomitant platinum-based chemoradiation which is better than conventional RT alone. However, some of the patients may develop a compromised bone marrow, after NACT, where further CT may not be possible. Accelerated RT with 6-fractions a week has shown better response rates than conventional 5-fractions a week. In light of the above factual matrix, the present study was planned to evaluate the efficacy, tolerability, and toxicity of NACT with TPF followed by concomitant chemoradiation in one group, accelerated RT in second group, and conventional RT in third group, in patients of LAHNC.

\section{SUBJECTS AND METHODS}

The present prospective, randomized, comparative, open label, parallel study was conducted on 75 previously untreated, histopathologically proven patients of SCC of head and neck. Patients included in the study were those having AJCC Stage III/IV and a positive biopsy for SCC of head and neck, Karnofsky Performance Status (KPS) $>70$, normal blood biochemistry, liver and kidney function test. The patients having distant metastases; prior radiation, surgery or CT for the disease; KPS $<60$; pregnant or lactating patient; associated medical conditions were excluded from the study.

Neoadjuvant chemotherapy

All 75 patients received NACT consisting of injection docetaxel $80 \mathrm{mg} / \mathrm{m}^{2}$, injection carboplatin $300 \mathrm{mg} / \mathrm{m}^{2}$, and injection 5-fluorouracil $600 \mathrm{mg} / \mathrm{m}^{2}$, every 3-weekly $\times$ 3-courses (total period 6-week).

\section{Group I}

It comprised 25 randomly selected patients who received NACT as mentioned above followed by concomitant conventional radical $\mathrm{RT}$, given five fractions per week, in total dose of $64 \mathrm{~Gy} / 32$ fractions/ 6.2 weeks (i.e. $2 \mathrm{~Gy} /$ fraction) along with 3 weekly carboplatin $300 \mathrm{mg} / \mathrm{m}^{2} \times 3$-cycles.

\section{Group II}

It comprised 25 randomly selected patients who received NACT as mentioned above followed by accelerated radical RT given six fractions per week, in a total dose of $64 \mathrm{~Gy} / 32$ fractions/5.2 weeks (i.e., 2 Gy/fraction).

\section{Group III}

It comprised 25 randomly selected patients having histopathologically proven squamous cell carcinomas of the head and neck who received NACT as mentioned above followed by conventional radical RT given five fractions per week, total dose $64 \mathrm{~Gy} / 32$ fractions/6.2 weeks (i.e. $2 \mathrm{~Gy} /$ fraction).

\section{Radiotherapy technique}

Radiotherapy was delivered in supine position by parallel opposing fields including the primary tumor, disease extension, and neck nodes. The shrinking field technique was used to spare the spinal cord after a dose of $44 \mathrm{~Gy}$. 
Malik, et al.: Chemoradiation versus accelerated versus conventional RT in LAHNC

\section{RESULTS}

\section{Patient characteristics}

Mean age at presentation in Group I, II, and III was 53-, 54-, and 56-year respectively. Overall, $92 \%$ patients were males, remaining $8 \%$ were females. Total male to female ratio was 11.5:1. Overall, $91 \%$ patients were from rural areas, whereas 9\% patients belonged to urban background.

In this study, overall 95\% patients were smokers (all more than 5-year history of smoking), whereas $5 \%$ patients were those who never smoked. Out of the total enrolled patients in all the groups, $68 \%$ were alcoholic. Total patients with KPS 80 were $13 \%$ and KPS 90 were $87 \%$. Throat pain was the most common chief complaint with $41 \%$ patients followed by difficulty in swallowing in $31 \%$ patients [Table 1].

\section{Tumor characteristics}

Oropharynx was most common primary International Classification of Diseases (ICD) site observed in $77 \%$ cases. Base of tongue was the most common primary ICD site in Group I (48\%) and Group III (48\%), whereas tonsil is the most common primary ICD site in Group II (32\%). According to the AJCC 2010 staging system, maximum patient were of T3 in Group I (76\%), Group II (64\%), and Group III (84\%). N2 was the most common nodal status at presentation in Group I (36\%) and Group II (44\%), whereas N1 and N2 were equally present in Group III (36\%). No status was seen in 7 patients (28\%) in all groups. Stage III patients were of maximum number in Group I (52\%) and Group III (60\%), but in Group II maximum patients belonged to Stage IV (64\%). The difference was not significant statistically and is attributable to randomization. Ulceroproliferative tumor $(77 \%)$ was found to be the most common type; indurated tumors were only $23 \%$ of all tumors. This study revealed that the most common histopathological subtype was moderately differentiated SCC being $78 \%$ in all groups followed by SCC (not otherwise specified): 15\%; followed by poorly differentiated SCC being 7\% [Table 2].

Hematological toxicity during neoadjuvant chemotherapy Hematological toxicity was assessed each time before NACT as per the WHO criteria. Hemoglobin $(\mathrm{Hb})$ was reduced in 13 out of 75 patients (17\%) after $1^{\text {st }}$ NACT and in 16 out of 75 patients (21\%) after $2^{\text {nd }}$ NACT. Only one patient in Group I (chemoradiotherapy) had Grade III anemia ( $\mathrm{Hb}=7.6 \mathrm{~g} \%$ ) after $2^{\text {nd }}$ NACT, hence decided to omit further course of NACT. There was no Grade IV anemia in any group at any time. During $3^{\text {rd }}$ NACT, Grade III neutropenia was seen in $40 \%$ patients in Group II, whereas in Group I and II, it was seen in $8 \%$ and $12 \%$ patients, respectively. During $2^{\text {nd }}$ NACT, Grade III neutropenia was seen in $8 \%, 20 \%$, and $4 \%$ in Groups I, II, and III, respectively. During $1^{\text {st }}$ NACT, Grade III neutropenia
Table 1: Patient characteristics

\begin{tabular}{|c|c|c|c|c|}
\hline $\begin{array}{l}\text { Patient } \\
\text { characteristics }\end{array}$ & $\begin{array}{c}\text { Group I } \\
(n=25) \\
\text { Concomitant } \\
\text { RT (\%) }\end{array}$ & $\begin{array}{c}\text { Group II } \\
(n=25) \\
\text { Accelerated } \\
\text { RT (\%) }\end{array}$ & $\begin{array}{c}\text { Group III } \\
\text { (n=25) } \\
\text { Conventional } \\
\text { RT (\%) }\end{array}$ & $P$ \\
\hline \multicolumn{5}{|l|}{ Age group (years) } \\
\hline$\leq 50$ & 40 & 48 & 36 & 0.734 \\
\hline$>50$ & 60 & 52 & 64 & \\
\hline \multicolumn{5}{|l|}{ Gender } \\
\hline Male & 96 & 92 & 88 & 0.581 \\
\hline Female & 4 & 8 & 12 & \\
\hline \multicolumn{5}{|l|}{ Background } \\
\hline Rural & 88 & 96 & 88 & 0.532 \\
\hline Urban & 12 & 4 & 12 & \\
\hline \multicolumn{5}{|l|}{ Smoking } \\
\hline Smoker & 96 & 96 & 92 & 0.768 \\
\hline Nonsmoker & 4 & 4 & 8 & \\
\hline \multicolumn{5}{|l|}{ KPS } \\
\hline 80 & 8 & 20 & 12 & 0.446 \\
\hline 90 & 92 & 80 & 88 & \\
\hline \multicolumn{5}{|l|}{ Symptoms } \\
\hline Dysphagia & 44 & 24 & 24 & 0.758 \\
\hline Neck mass & 16 & 16 & 16 & \\
\hline Breathlessness & 0 & 0 & 4 & \\
\hline Nonhealing ulcer & 0 & 4 & 4 & \\
\hline Hoarseness & 12 & 8 & 4 & \\
\hline Throat pain & 28 & 48 & 48 & \\
\hline
\end{tabular}

RT - Radiotherapy; KPS - Karnofsky performance status

Table 2: Tumor characteristics

\begin{tabular}{|c|c|c|c|c|}
\hline Tumor characteristics & $\begin{array}{c}\text { Group I } \\
\text { (n=25) } \\
\text { Concomitant } \\
\text { RT (\%) }\end{array}$ & $\begin{array}{c}\text { Group II } \\
(n=25) \\
\text { Accelerated } \\
\text { RT (\%) }\end{array}$ & $\begin{array}{c}\text { Group III } \\
\text { (n=25) } \\
\text { Conventional } \\
\text { RT }(\%)\end{array}$ & $P$ \\
\hline \multicolumn{5}{|l|}{ Morphology } \\
\hline Ulceroproliferative & 68 & 80 & 84 & 0.372 \\
\hline Indurated & 32 & 20 & 16 & \\
\hline \multicolumn{5}{|l|}{ Histopathology } \\
\hline WDSCC & 0 & 0 & 0 & 0.884 \\
\hline MDSCC & 76 & 80 & 80 & \\
\hline PDSCC & 4 & 8 & 8 & \\
\hline SCC (NOS) & 20 & 12 & 12 & \\
\hline \multicolumn{5}{|l|}{ Site of tumor } \\
\hline Oral cavity & 0 & 12 & 0 & 0.078 \\
\hline Oropharynx & 68 & 80 & 84 & \\
\hline Hypopharynx & 12 & 0 & 4 & \\
\hline Larynx & 20 & 8 & 12 & \\
\hline \multicolumn{5}{|l|}{ Stage-wise distribution } \\
\hline III & 52 & 36 & 60 & 0.225 \\
\hline IV & 48 & 64 & 40 & \\
\hline
\end{tabular}

RT - Radiotherapy; MDSCC - Moderately differentiated squamous cell carcinoma; WDSCC - Well differentiated squamous cell carcinoma; PDSCC - Poorly differentiated squamous cell carcinoma; SCC - Squamous cell carcinoma; NOS - Not otherwise specified

was seen only in Group I (4\%) and Group II (8\%). During $3^{\text {rd }}$ NACT, Grade III thrombocytopenia was seen in $42 \%$ patients in Group I, 28\% patients in Group II and 36\% patients in 
Malik, et al.: Chemoradiation versus accelerated versus conventional RT in LAHNC

Group III. There was only one patient of Group III, who had Grade IV thrombocytopenia. Hence, overall the compliance to NACT with TPF was good.

\section{Response rates postneoadjuvant chemotherapy}

Overall $100 \%$ response rate was seen in all groups, to three cycles of NACT. Complete response after three NACT was seen in $12 \%$ patients in Group I, 20\% patients in Group II, and $12 \%$ patients in Group III, $P=0.653$ (not significant) [Table 3].

Hematological toxicity during concomitant chemotherapy Hematological toxicity was assessed each time before three cycles of concomitant CT given in Group I of study. There was no Grade III anemia seen in any group at any time during concomitant CT. Grade III neutropenia was seen in $74 \%$ patients and Grade III thrombocytopenia was seen in 56\% patients during concomitant CT. Two patients received only one cycle of concomitant CT.

Acute radiation reactions observed during radiotherapy Radiation reactions in all patients were noted during and after radiation treatment completion and were graded as per the Radiation Therapy Oncology Group (RTOG) grades. Grade III skin reaction was seen in 21\% patients in Group II, $17 \%$ in Group I and only $4 \%$ patients in Group III at completion of radiotherapy $(P=0.197)$. None of the patients developed Grade IV skin reactions. RTOG Grade III mucositis observed at end of treatment was seen in 33\% patients in Group II, 22\% patients in Group I, and 4\% patients in Group III $(P=0.033$ statistically significant). Grade IV mucosal reactions were not seen in any of the patients.

Patients completing intended treatment

Two patients (8\%) in Group I (concomitant RT) did not complete the intended treatment and left after 13\# and 9\# of RT getting only 26 Gy and 18 Gy respectively out of intended $64 \mathrm{~Gy}$, due to nontolerability of concomitant chemoradiation as they developed severe nausea and vomiting after the $1^{\text {st }}$ cycle of concomitant chemotherapy (CCT). One patient (4\%) in Group II (accelerated RT) left the treatment after getting 8 Gy (4\#) due to Grade III mucositis.

\section{Disease status at 1 month follow-up}

Locoregional control and disease status at 1 month follow-up was assessed in all patients [Table 4]. Complete tumor response was seen in $16(69 \%)$ patients in Group I, $14(59 \%)$ patients in group in II, and $15(60 \%)$ patients in Group III, at $1^{\text {st }}$ month of follow-up, $P=0.693$ (not significant). Complete nodal response was seen in 11 (65\%) patients in Group I, 10 (59\%) patients in Group II, and 10 (56\%) patient in Group III at 1 month of follow-up, $P=0.849$ (not significant). Overall complete response was seen in
Table 3: Response rates post-neoadjuvant chemotherapy

\begin{tabular}{lccc}
\hline $\begin{array}{l}\text { Response } \\
\text { rates }(\%)\end{array}$ & Group I $(\boldsymbol{n}=\mathbf{2 5 )}$ & $\begin{array}{c}\text { Group II } \\
(\boldsymbol{n}=\mathbf{2 5})\end{array}$ & $\begin{array}{c}\text { Group III } \\
(\boldsymbol{n}=\mathbf{2 5 )}\end{array}$ \\
\hline CR & 12 & 20 & 12 \\
PR & 88 & 80 & 88 \\
Overall & 100 & 100 & 100 \\
\hline
\end{tabular}

CR - Complete response; PR - Partial response

Table 4: Disease status at 1 month follow-up

\begin{tabular}{llccc}
\hline Groups & Stage & Total patients & \multicolumn{2}{c}{ Disease status (\%) } \\
\cline { 4 - 5 } & & & CR & PR \\
\hline Group I & III & $11^{*}$ & 26 & 22 \\
& IV & 12 & 39 & 13 \\
& All stages & $23^{*}$ & 65 & 35 \\
Group II & III & 9 & 16 & 21 \\
& IV & $15^{* *}$ & 38 & 25 \\
& All stages & $24^{* *}$ & 54 & 46 \\
Group III & III & 15 & 36 & 24 \\
& IV & 10 & 16 & 24 \\
& All stages & 25 & 52 & 48 \\
\hline
\end{tabular}

${ }^{*}$ Two patients left treatment in Group I; ** One patient left treatment in Group II. CR - Complete response; PR - Partial response

$15(65 \%)$ patients in Group I, 13 (54\%) patients in Group II, and $13(52 \%)$ patient in Group III at 1 month of follow-up, $P=0.617$ (not significant).

\section{Disease status at last follow-up}

Complete tumor response was seen in $15(65 \%)$ patients in Group I, 13 (54\%) patients in Group III, and 13 (52\%) patients in Group III at last follow-up, $P=0.617$ (not significant). Complete nodal response was seen in 10 (59\%) patients in Group I and II and 9 (47\%) patients in Group III at last follow-up, $P=0.858$ (not significant). For all stages, no evidence of disease (NED), in Group I, II, and III, respectively, was $52 \%(12 / 23), 46 \%(11 / 24)$, and $40 \%(10 / 25)$. For all stages, residual disease was seen in 39\% (9/23) of patients in Group I, $46 \%(11 / 24)$ patients in Group II, and 44\% (11/25) patients in Group III. Recurrence was seen in 9\% patients in Group I, 8\% patients in Group II, whereas it was seen in $16 \%$ patients in Group III, $P=0.699$ (not significant) [Table 5].

\section{Late radiation reactions}

Worst grade late subcutaneous toxicity (Grade II) was seen in 26\% patients in Group I, 17\% patients in Group II, and 8\% patients in Group III. Worst grade late mucosal toxicity (Grade II) was seen only in Group I in 9\% patients. Worst grade late salivary gland toxicity (Grade II) was seen in 13\% patients in Group I, 13\% patients in Group II, and 8\% patients in Group III.

Disease free survival

Disease free survival (DFS) for all stages was 12/23 (52\%) in Group I, 11/24 (46\%) in Group II, and 10/25 (40\%) in Group III, $P=0.699$ (not significant) [Table 6]. 


\section{DISCUSSION}

The main objective of the study was to evaluate and compare the efficacy, tolerability, and toxicity of NACT with TPF followed by concomitant chemoradiation and their comparison with other two groups. Accordingly, we have explored the International Medical Literature and compared the results of our study to conclude the feasibility of the present study.

Majority of head and neck malignant neoplasms arise from the surface epithelium and are SCC or one of its variants, such as lymphoepithelioma, spindle cell carcinoma, verrucous carcinoma, and undifferentiated carcinoma. ${ }^{[1]}$ People who use tobacco (including cigarettes, cigars, pipes, etc.,) or drink alcohol excessively are at much greater risk for developing HNCs. ${ }^{[3,4]}$ Approximately, $70-80 \%$ of these patients are diagnosed with locally advanced disease and $30-50 \%$ with lymph node involvement. ${ }^{[12]}$ Stage at diagnosis is the single most important determinant of prognosis. The 5 -year survival for Stage I patients exceeds $80 \%$ but is $<40 \%$ in LAHNC. NACT with TPF is better than PF only schedule in LAHNC; hence, we used this schedule in our study. Various famous trials are in support of this like Posner et al., conducted a

Table 5: Disease status at last follow-up

\begin{tabular}{llcccc}
\hline Group & Stage & $\begin{array}{c}\text { Total number } \\
\text { of patients }\end{array}$ & \multicolumn{3}{c}{ Disease status (\%) } \\
\cline { 4 - 6 } & & $11^{*}$ & 22 & 22 & 4 \\
\hline Group I $(n=23)^{*}$ & III & 12 & 30 & 17 & 4 \\
& IV & $23^{*}$ & 52 & 39 & 9 \\
& All stages & 9 & 17 & 21 & 0 \\
Group II $(n=24)^{*}$ & III & $15^{* *}$ & 29 & 25 & 8 \\
& IV & $24^{* *}$ & 46 & 46 & 8 \\
& All stages & 15 & 28 & 24 & 8 \\
Group III $(n=25)$ & III & 10 & 12 & 20 & 8 \\
& IV & 25 & 40 & 44 & 16 \\
& All stages & 72 & 46 & 43 & 11 \\
\hline
\end{tabular}

${ }^{*}$ Two patients left treatment in Group I; ${ }^{* *}$ One patient left treatment in Group II. NED - No evidence of disease; RD - Residual disease; REC - Recurrence; NED - No evidence of disease randomized phase III trial for the treatment of head and neck SCC to compare induction CT with TPF with PF, followed by chemoradiation. There was a better locoregional control in the TPF group, but the incidence of distant metastases in the two groups did not differ significantly. Rates of neutropenia and febrile neutropenia were higher in the TPF group; CT was more frequently delayed because of hematologic adverse events in the PF group. ${ }^{[13]}$ Similarly, in a phase II comparative study of TPF versus PF as induction CT in 358-patients of LAHNC. At a median follow-up of 32.5 months, the median progression-free survival (PFS) was 11.0 months in the TPF group and 8.2 months in the PF group. Treatment with TPF resulted in a reduction in the risk of death of $27 \%$, with a median overall survival (OS) of 18.8 months, as compared with 14.5 months in the PF group. ${ }^{[14]}$

In a further study, the effectiveness of induction CT with TPF followed by radiation was compared with that of concurrent chemoradiation with TPF in LAHNC patients and concluded that the effectiveness of concurrent chemoradiation with TPF was better than that of induction CT with TPF followed by radiation. ${ }^{[15]}$

Haddad et al. conducted a series of four Phase I-II trials of high-dose and intermediate-dose TPF-based induction CT on 101 LAHNC patients. After a median follow-up of 49 months, $64 \%$ remain alive with NED, and 3 patients remain alive with disease, for an OS rate of $67 \%$. Twenty-six patients had locoregional recurrences, and 5 patients had both LRR and distant metastasis. Out of 84 patients, 55 patients remain alive with NED (65\%). Notably, 43 of 84 patients (51\%) had oropharyngeal primary tumors, and 30 of those patients remain alive with NED $(70 \%)$. Significant morbidity was low, with two treatment-related deaths. These data suggest that docetaxel adds incrementally to the efficacy of cisplatin and fluorouracil. ${ }^{[16]}$

The importance of even small amount of acceleration was emphasized by the results from the Danish Head and

Table 6: Disease free survival

\begin{tabular}{|c|c|c|c|c|c|c|}
\hline \multirow[t]{2}{*}{ Disease free survival/status } & \multicolumn{2}{|c|}{$\begin{array}{c}\text { Group I } \\
\text { (concomitant chemoradiation) }\end{array}$} & \multicolumn{2}{|c|}{$\begin{array}{c}\text { Group II } \\
\text { (accelerated RT) }\end{array}$} & \multicolumn{2}{|c|}{$\begin{array}{c}\text { Group III } \\
\text { (conventional RT) }\end{array}$} \\
\hline & $\begin{array}{l}\text { Stage } \\
\text { III }(n=11)\end{array}$ & Stage IV $(n=12)$ & Stage III $(n=9)$ & Stage IV $(n=15)$ & $\begin{array}{c}\text { Stage } \\
\text { III }(n=15)\end{array}$ & Stage IV $(n=10)$ \\
\hline Locoregional failure & 5 & 4 & 5 & 6 & 6 & 5 \\
\hline Distant metastasis & 0 & 0 & 0 & 0 & 0 & 0 \\
\hline Local recurrence & 1 & 1 & 0 & 2 & 2 & 2 \\
\hline Locoregional control (stage wise) & $5 / 11$ & $7 / 12$ & $4 / 9$ & $7 / 15$ & $7 / 15$ & $3 / 10$ \\
\hline Locoregional control (all stages) & \multicolumn{2}{|c|}{$12 / 23$} & \multicolumn{2}{|c|}{$11 / 24$} & \multicolumn{2}{|c|}{$10 / 25$} \\
\hline Disease free survival & \multicolumn{2}{|c|}{$12 / 23^{*}(52 \%)$} & \multicolumn{2}{|c|}{$11 / 24^{* *}(46 \%)$} & \multicolumn{2}{|c|}{$10 / 25(40 \%)$} \\
\hline
\end{tabular}

*Two patients left treatment in Group I; **One patient left treatment in Group II. RT - Radiotherapy 
Malik, et al.: Chemoradiation versus accelerated versus conventional RT in LAHNC

Neck Cancer Study Group 6 and 7 trial. In the Danish trial, Overgaard et al. aimed to find out whether shortening of treatment time by the use of six instead of five radiotherapy fractions per week improves the tumor response in SCC. Overall 5-year locoregional control rates improved $(70 \%$ vs. $60 \% ; P=0.0005)$. The benefit of shortening treatment time was seen for primary tumor control (76\% vs. $64 \% ; P=0.0001)$, but not for neck-node control. Acceleration from 7 to 6 weeks improved voice preservation in laryngeal cancer $(80 \%$ vs. $68 \% ; P=0.007)$ and improved disease-specific survival (73\% vs. $66 \% ; P=0.01)$ but not OS. Acute morbidity was significantly more frequent with six than with five fractions, but was transient. ${ }^{[17]}$

Bourhis et al. did an analysis of two randomized trials of the French Head and Neck Cancer Group to compare concomitant chemoradiation and accelerated radiotherapy comparing conventional RT (70 Gy in 35 fractions) either with concomitant RT-CT (70 Gy in 35 fractions with three cycles of a 4-day regimen comprising carboplatin and 5 -fluorouracil) or with very accelerated RT delivering $64 \mathrm{~Gy}$ in 3 weeks. The 5-year OS, specific DFS, and local-regional control rates were improved in favor of simultaneous RT-CT, whereas local-regional control was significantly improved with accelerated RT, along with a marginal effect on OS and DFS. They concluded that both concomitant chemoradiation and accelerated RT improved tumor control rates, as compared to conventional RT, along with increased but manageable toxicity. ${ }^{[18]}$ In a further Phase III randomized trial on LAHNC with an Eastern Cooperative Oncology Group performance status of $0-2$, accelerated radiotherapy- CT offered no PFS benefit compared with conventional chemoradiation or very accelerated radiotherapy; conventional chemoradiation improved PFS compared with very accelerated radiotherapy. Three-year PFS was $37 \cdot 6 \%$ after conventional chemoradiation, $34 \cdot 1 \%$ after accelerated radiotherapy-CT, and $32 \cdot 2 \%$ after very accelerated radiotherapy. They concluded that CT has a substantial treatment effect given concomitantly with radiotherapy and acceleration of radiotherapy cannot compensate for the absence of $\mathrm{CT}^{\mid{ }^{\mid 19]}}$

\section{CONCLUSION}

The present study was a feasibility study and have shown better complete response in Group II (Accelerated RT) than group III but was associated with severe acute radiation toxicity especially mucosal which was statistically significant too. Group III (Conventional RT) treatment schedule was tolerated by all the patients without significant problems however it yielded the least local control out of the three groups. Group I (Concomitant chemoradiation) showed better complete response than other two groups with toxicity profile more acceptable than group II. It is concluded that following neoadjuvant chemotherapy, concomitant chemoradiation is better schedule as compared to accelerated radiation therapy or conventional radiotherapy.

Financial support and sponsorship

Nil.

Conflicts of interest

There are no conflicts of interest.

\section{REFERENCES}

1. Ferlay J, Soerjomataram I, Ervik M, Dikshit R, Eser S, Mathers C, et al. GLOBOCAN 2012 v1.0, Cancer Incidence and Mortality Worldwide: IARC Cancer Base No. 11. Lyon, France: International Agency for Research on Cancer; 2013. Available from: http://www.globocan.iarc. fr. [Last accessed on 2014 Nov 09].

2. Bose P, Brockton NT, Dort JC. Head and neck cancer: From anatomy to biology. Int J Cancer 2013;133:2013-23.

3. Memorial Sloan Kettering Cancer Centre. Head and Neck Cancers: Risk, Prevention and Screening. Available from: http://www.mskcc.org/ cancer-care/adult/head-neck/risk-prevention-screening. [Last accessed on 2014 Nov 01].

4. Dhull AK, Atri R, Kaushal V, Malik G, Soni A, Dhankhar R, et al. Alcohol as a risk factor in $\mathrm{HNC}$, an enormous toll on the lives and communities. J Evid Based Med Healthc 2016;3:354-60.

5. Waes CV, Haglund KE, Conley BA. Head and neck cancer. In: Abraham J, Gulley JL, Allegra CJ, editors. The Bethesda Handbook of Clinical Oncology. $4^{\text {th }}$ ed. Philadelphia, USA: Lippincott Williams and Wilkins, Wolters Kluwer Business; 2014. p. 1-30.

6. Murphy BA. Carcinomas of head and neck. In: Skeel RT, Khleif SN, editors. Handbook of Cancer Chemotherapy. $8^{\text {th }}$ ed. New Delhi, India: Lippincott Williams and Wilkins, Wolters Kluwer (India) Pvt. Ltd.; 2011. p. 69-93.

7. Kuperman D, Arquette M, Adkins D. Head and neck cancer. In: Govindan R, editor. The Washington Manual of Oncology. $2^{\text {nd }}$ ed. Philadelphia, USA: Lippincott Williams and Wilkins, Wolters Kluwer Business; 2008. p. 119-34.

8. Hall EJ, Giaccia AJ. Radiobiology for the Radiologist. $7^{\text {th }}$ ed. Philadelphia, USA: Lippincott Williams and Wilkins, Wolters Kluwer Business; 2012.

9. Nwizu T, Adelstein DJ. In squamous cell head and neck cancer: Which platinum, how much and how often? Expert Rev Anticancer Ther 2014;14:1033-9.

10. Ahamad A. Altered fractionation schedules. In: Halperin EC, Wazer DE, Perez CA, Brady LW, editors. Perez and Brady's Principles and Practice of Radiation Oncology. $6^{\text {th }}$ ed. Philadelphia, USA: Lippincott Williams and Wilkins, Wolters Kluwer Business; 2013. p. 278-96.

11. Mendenhall WM, Werning JW, Pfister DG. Treatment of head and neck cancer. In: Devita VT, Lawrence TS, Rosenberg SA, editors. Cancer Principles and Practice Oncology. $9^{\text {th }}$ ed. Philadelphia, USA: Lippincott Williams and Wilkins, Wolters Kluwer Business; 2011. p. 729-80.

12. Kanotra SP, Kanotra S, Gupta A, Paul J. Chemoradiation in Advanced Head and Neck Cancers: A comparison of two radiosensitizers, paclitaxel and cisplatin. Indian J Otolaryngol Head Neck Surg 2011;63:229-36.

13. Posner MR, Hershock DM, Blajman CR, Mickiewicz E, Winquist E, 
Malik, et al.: Chemoradiation versus accelerated versus conventional RT in LAHNC

Gorbounova V, et al. Cisplatin and fluorouracil alone or with docetaxel in head and neck cancer. N Engl J Med 2007;357:1705-15.

14. Vermorken JB, Remenar E, van Herpen C, Gorlia T, Mesia R, Degardin $\mathrm{M}$, et al. Cisplatin, fluorouracil, and docetaxel in unresectable head and neck cancer. N Engl J Med 2007;357:1695-704.

15. Katori H, Tsukuda M. Comparison of induction chemotherapy with docetaxel, cisplatin, and 5-fluorouracil (TPF) followed by radiation vs concurrent chemoradiotherapy with TPF in patients with locally advanced squamous cell carcinoma of the head and neck. Clin Oncol (R Coll Radiol) 2005;17:148-52.

16. Haddad R, Colevas AD, Tishler R, Busse P, Goguen L, Sullivan C, et al. Docetaxel, cisplatin, and 5-fluorouracil-based induction chemotherapy in patients with locally advanced squamous cell carcinoma of the head and neck: The Dana Farber Cancer Institute experience. Cancer 2003;97:412-8.
17. Overgaard J, Hansen HS, Specht L, Overgaard M, Grau C, Andersen E, et al. Five compared with six fractions per week of conventional radiotherapy of squamous-cell carcinoma of head and neck: DAHANCA 6 and 7 randomised controlled trial. Lancet 2003;362:933-40.

18. Bourhis J, Calais G, Lapeyre M, Tortochaux J, Alfonsi M, Sire C, et al. Concomitant radiochemotherapy or accelerated radiotherapy: Analysis of two randomized trials of the French Head and Neck Cancer Group (GORTEC). Semin Oncol 2004;31:822-6.

19. Bourhis J, Sire C, Graff P, Grégoire V, Maingon P, Calais G, et al. Concomitant chemoradiotherapy versus acceleration of radiotherapy with or without concomitant chemotherapy in locally advanced head and neck carcinoma (GORTEC 99-02): An open-label phase 3 randomised trial. Lancet Oncol 2012;13:145-53. 